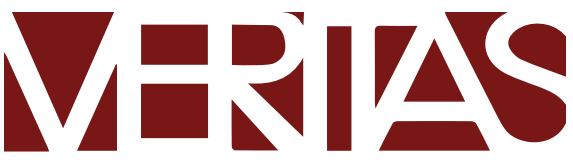

$\begin{array}{lllllllllll}P & O & R & T & O & A & L & E & G & R & E\end{array}$

http://dx.doi.org/10.15448/1984-6746.2019.2.32882

\title{
AXEL HONNETH E A SUA TEORIA PLURAL DA JUSTIÇA
}

\author{
Axel Honneth and his plural theory of justice \\ Axel Honneth y su teoría plural de la justicia
}

Paulo Vitorino Fontes ${ }^{1}$

Centro de Investigação em Ciência Política

das Universidades do Minho e de Évora, Minho/Évora, Portugal.

\section{Resumo}

Axel Honneth desenvolve o conceito de reconhecimento, encarado como uma necessidade fundamental do ser-humano, de forma a constituir-se no núcleo de uma teoria da justiça que procura especificar as condições intersubjetivas de autorrealização individual. Apresenta-se uma teoria da justiça assente na reconstrução das práticas e condições de reconhecimento já institucionalizadas, analisando as instituições sociais em um sentido amplo. Pretende-se aproximar a concepção normativa da justiça da análise sociológica das sociedades modernas, através da reconstrução normativa e ao colocar a ênfase na liberdade social, baseada na dimensão intersubjetiva das instituições de reconhecimento. A liberdade social prevê o acesso às instituições de reconhecimento. Um dos objetivos é esboçar os problemas desse avanço interpretativo da teoria crítica do reconhecimento, pelo que iremos convocar a teoria da luta pelo reconhecimento

Doutor em Teoria Jurídico-Política e Relações Internacionais. Membro colaborador do Centro de Investigação em Ciência Política das Universidades do Minho e de Évora (CICP), Minho/Évora, Portugal. http://orcid.org/0000-0002-1443-6820. E-mail: pfontes@uevora.pt 
de Honneth, incluir a sua reactualização mais recente do Direito de Hegel e explorar a sua proposta normativa para as condições de uma vida ética.

Palavras-chave: Honneth. Reconhecimento. Justiça. Reconstrução normativa

\begin{abstract}
Axel Honneth develops the concept of recognition, seen as a fundamental need of the human being, in order to be at the core of a theory of justice that seeks to specify the intersubjective conditions of individual self-realization. It presents a theory of justice based on the reconstruction of practices and conditions of recognition already institutionalized, analyzing social institutions in an ample sense. The aim is to bring the normative conception of justice closer to the sociological analysis of modern societies through normative reconstruction and to place emphasis on social freedom based on the intersubjective dimension of recognition institutions. Social freedom provides access to recognition institutions. One of our objectives is to sketch the problems of this interpretative advance of a critical theory of recognition, so we will summon the theory of the struggle for recognition of Honneth, includinghis most recent actualization of Hegel's Law, and explore his normative proposal for the conditions of an ethical life.
\end{abstract}

Keywords: Honneth. Recognition. Justice. Normative reconstruction.

\title{
Resumen
}

Axel Honneth desarrolla el concepto de reconocimiento, visto como una necesidad fundamental del ser-humano, con el fin de constituir el núcleo teoría de la justicia que busca especificar las condiciones intersubjetivas de la autorrealización individual. Se presenta una teoría de la justicia basada en la reconstrucción de las prácticas y condiciones del reconocimiento ya institucionazadas, analizando las instituciones sociales en un sentido amplio. Se pretende, además, acercarce a la concepción normativa de la justicia desde la análisis sociológica de las sociedades modernas, a través de la reconstrucción normativa y al colocar la énfasis en la libertad social, basado en la dimensión intersubjetiva de las instituciones del reconocimiento. La libertad social preve el acceso a las instituciones de reconocimiento. Uno de nuestros objetivos es exponer los problemas de este avance interpretativo de la teoría crítica del reconocimiento, motivo por lo cual iremos convocar la teoría de la lucha por el reconocimiento de Honneth, incluyendo la última reactualización del Derecho de Hegel y explorar su propuesta normativa para las condiciones de una vida ética.

Palabras clave: Honneth. Reconocimiento. Justicia. Reconstrucción normativa. 


\section{Introdução}

A teoria do reconhecimento de Honneth ganha cada vez mais importância nos ciclos académicos anglo-saxónicos, europeus e latino-americanos. Destacada figura na academia alemã, Honneth inscreve-se dentro da teoria crítica e é o atual diretor do Instituto de Investigação Social, tradicionalmente associado à Escola de Frankfurt. Juntamente com Charles Taylor, Axel Honneth revitalizou a referência a Hegel na filosofia política contemporânea, principalmente a partir da sua obra A luta pelo reconhecimento em 1992. O giro teórico que Honneth imprimiou à teoria crítica consistiu em desenvolver a categoria hegeliana do "reconhecimento" como a ferramenta conceptual mais adequada a revelar as experiências sociais de injustiça e a compreender a fonte motivacional das lutas sociais. Atualmente, Honneth está preocupado em encontrar, para além de uma explicação genética das demandas sociais, um ponto de vista normativo, a partir do qual seja possível avaliar quais as reivindicações que são justas e legítimas e quais as que não o são.

Honneth desenvolve o núcleo de uma teoria da justiça que procura especificar as condições intersubjetivas de autorrealização individual, ou seja, uma teoria da justiça que esteja vinculada não a modelos abstratos, mas a uma reconstrução das práticas e condições de reconhecimento já institucionalizadas, analisando as instituições sociais um sentido amplo. $\mathrm{O}$ autor propõe a ultrapassagem do hiato entre uma conceção normativa da justiça e a análise sociológica das sociedades modernas, ao propor a reconstrução normativa e ao colocar a ênfase na liberdade social, baseada na dimensão intersubjetiva das instituições de reconhecimento. A liberdade social prevê o acesso às instituições de reconhecimento. Um dos nossos objetivos é esboçar os problemas desse avanço interpretativo. Como aceder de maneira equitativa às instituições de reconhecimento? E serão essas instituições estruturalmente injustas? Eis ainda outro ponto problemático que repousa sobre a proposta de reconstrução do princípio normativo de justiça que guia as pessoas a participar das esferas de reconhecimento e cooperação, 
sem se colocar a questão se são intrínseca e estruturalmente justas. Como pensar a possibilidade de justiça ao participar nessas instituições?

Se nos países europeus a crise do estado de bem-estar demanda um retorno à discussão da questão social com um novo compromisso capaz de prevenir a desintegração social e a exclusão, no Brasil e noutros países do Sul as demandas são ainda mais prementes diante da desigualdade de recursos tanto materiais como simbólicos, que impedem de se aceder à busca por formas de igualdade vital e existencial. Assim, conforme indicado por pesquisas empíricas e teóricas, novos programas redistributivos poderão certamente contribuir nesse sentido, ao diminuir a pobreza e a desigualdade e ao garantir condições básicas necessárias para promover as lutas contra as desigualdades vitais e existenciais.

\section{Reconhecimento}

A ideia de uma luta por reconhecimento como chave metodológica para a compreensão dos conflitos sociais foi inicialmente elaborada por Georg Wilhelm Friedrich Hegel durante o período denominado de "Jena", como referência à sua estadia na cidade homónima, bem como ao instrumento teórico que elaborou, como jovem docente de Filosofia, cujo fundamento interno ultrapassa o horizonte institucional do seu tempo (HONNETH (2011, p. 13). É a partir daqui que Honneth procura a possibilidade de fundar uma nova teoria social com conteúdo normativo, seguindo a linha do anterior contributo de Max Horkheimer para a teoria crítica. Neste sentido, Honneth (2007b) pretende ligar o seu projeto à tradição filosófica do "hegelianismo de esquerda", onde se incluem numerosos autores e autoras, podendo-se destacar alguns pensadores como Marx, Adorno e Habermas.

A partir da releitura dos teóricos de Frankfurt, Honneth propõe a existência de três pressupostos que atravessam sua crítica: 1) a declaração de uma razão universal capaz de tornar inteligíveis os movimentos sociais; 2) a atuação discordante desta razão como causa de uma patologia; e 3 ) um móbil emancipatório identificado a partir de um sofrimento (HONNETH, 2009a). 
Os dois primeiros pressupostos são abertos e, assim, não é possível aferir a sua comprovação empírica. É apenas a partir do último pressuposto teórico que se pode facultar à teoria um conteúdo positivo, objeto de experimentação. Desta forma, Honneth propõe a construção de uma teoria social com conteúdo normativo, dependente da capacidade de verificação pré-teórica do sofrimento social, capaz de informar o pensamento teórico da pertinência de uma vontade emancipatória na sociedade.

No entanto, segundo Honneth (2007b,), a Escola de Frankfurt continuara presa ao materialismo histórico marxista, aliando o sofrimento social às questões particulares de uma classe, a proletária, a quem competiria transformar o seu sofrimento em motor emancipatório. Mas quando a história demonstrara que a classe proletária tinha transformado o seu sofrimento no apoio à ascensão do fascismo, o teor positivo inicialmente adotado pela teoria crítica tinha-se tornado desajustado à compreensão e à transformação da sociedade.

Contudo, para Honneth o que a história demonstra como inadequado é apenas o conteúdo positivo específico adotado pela teoria, que estava ligado à exploração do trabalho e não a sua fundamentação teórica, permanecendo em aberto a possibilidade de desenvolver uma teoria social de conteúdo normativo, desde que se parta do sofrimento como revelador de uma vontade emancipatória na sociedade. Para este pensador, sem algum tipo de prova que a perspetiva crítica da teoria é reforçada por um movimento na realidade social, a teoria crítica deixa de poder ser seguida na contemporaneidade, uma vez que não seria possível distingui-la de outros modelos de crítica social, quer pela sua reivindicação de um método sociológico superior quer pelos seus procedimentos filosóficos de justificação. Para Honneth (2007b), é somente pela sua tentativa, que ainda não foi abandonada, de fornecer à crítica um fundamento objetivo na práxis pré-teórica que se pode dizer que a teoria crítica é única e está viva.

A partir deste exercício, Honneth levanta críticas à teoria da ação comunicativa de Habermas, precisamente por não encontrar suporte no diagnóstico claro do sofrimento social. Defende que se a comunicação for 
afastada da teoria da linguagem e entendida como processo intersubjetivo, por meio do qual a identidade humana se desenvolve, este sofrimento pode ser percebido no reconhecimento deficitário de algumas identidades e, assim, a crítica reencontraria nesse reconhecimento o seu suporte normativo perdido (HONNETH, 2007b,). Afigura-se, então, o resgate do projeto filosófico hegeliano de uma luta por reconhecimento.

No prolongamento teórico de Honneth (2011), percebemos um esforço de conceptualização das três esferas do reconhecimento: Amor, Direito e Estima Social, inicialmente identificadas por Hegel. Estas esferas de interação, através da aquisição cumulativa de autoconfiança, auto respeito e autoestima, criam não só as condições sociais para que os indivíduos possam chegar a uma atitude positiva para com eles mesmos, como também originam o indivíduo autónomo.

A esfera do amor constitui as relações afetivas primárias de reconhecimento mútuo que estruturam o indivíduo desde o nascimento, e que se encontram dependentes de um balanço frágil entre autonomia e vinculação. Segundo Honneth (2011, p. 131-146), o vínculo alimentado simbioticamente, que se forma por uma delimitação reciprocamente desejada inicialmente entre a mãe e filho, cria a dimensão de autoconfiança individual, que será a base fundamental para a participação autónoma na vida pública.

A partir da perspetiva normativa do outro generalizado, que nos ensina a reconhecer os outros enquanto titulares de direitos, é nos permitido compreender a nós próprios enquanto pessoas jurídicas. A esfera do Direito desenvolve-se em um processo histórico, o seu potencial de desenvolvimento verifica-se na generalização e na materialização das relações de reconhecimento jurídico (HONNETH, 2011).

Para se poder atingir um auto relacionamento ininterrupto, os sujeitos humanos também necessitam sempre, além da experiência da dedicação afetiva e do reconhecimento jurídico, de uma valorização social que lhes permita relacionarem-se positivamente com as suas propriedades e capacidades concretas. Estamos na esfera da estima social, de uma terceira relação do reconhecimento recíproco, a partir do pressuposto da valorização simétrica, 
os indivíduos consideram-se reciprocamente à luz de valores que tornam manifestas as capacidades e as propriedades de si e do outro como importantes para a experiência comum. A relação simétrica não significa uma valorização recíproca em igual medida, mas sim o desafio de que qualquer sujeito tem a oportunidade de se experimentar como valioso para a sociedade através das suas capacidades e propriedades. Só assim, seguindo o raciocínio de Honneth (2011), sob a noção de solidariedade é que as relações sociais poderão aceder a um horizonte em que a concorrência individual pela valorização social poderá estar isenta de experiências de desrespeito.

Na sucessão das três formas de reconhecimento, o grau da relação positiva da pessoa consigo mesma aumenta progressivamente. Com cada nível da consideração mútua cresce também a autonomia subjetiva do indivíduo. De igual forma, às correspondentes formas de reconhecimento mútuo, poder-se-á atribuir experiências paralelas de desrespeito social.

No seu artigo "Invisibilité: sur l'épistémologie de la reconnaissance", Honneth (2005) apresenta a invisibilidade como a negação da noção de reconhecimento. O conceito e o início da discussão inspiram-se no livro de Ralph Ellison, El hombre invisible (1984) e baseia-se na experiência de uma personagem negra que sofre um processo de "invisibilização" por parte da sociedade branca.

Partindo de uma ideia metafórica, Honneth mostra que a invisibilidade é um processo ativo, no qual se evidencia o desprezo: um comportamento relativo a uma pessoa como se esta não estivesse e que, para ela, torna-se muito real. A visibilidade, pelo contrário, significa reconhecer as caraterísticas relevantes de uma pessoa. Deste modo, Honneth (2005) apresenta a identificabilidade individual como a primeira forma de conhecimento. Este estádio já é considerado um ato social, uma vez que o indivíduo afetado sabe da sua invisibilidade pela falta de reações específicas por parte do outro ou dos outros. Para além disso, a falta de atos expressivos de visibilidade também pode ser percebida pelas outras pessoas presentes. Pelo que, pode-se falar de uma invisibilidade social, o que conduz Honneth a uma diferenciação entre "conhecer" e "reconhecer": 
"conhecer" é então a identificação não pública de um indivíduo, enquanto "reconhecer" refere-se à apreciação como ato público.

De maneira análoga às contribuições de Daniel Stern (1992) sobre o desenvolvimento interpessoal dos bebés, Honneth afirma que também para os adultos existem sinais que mostram abertamente se foram aprovados socialmente. Como prova pode-se considerar justamente aquele sentimento que se produz nas situações em que se nega a uma pessoa esta aprovação. Todas as expressões de aprovação são interpretadas como um sinal, em uma forma simbolicamente abreviada, de toda uma série de disposições que fazem referência a um conjunto de atuações que se podem esperar legitimamente nas interações futuras, como por exemplo ser tratado com respeito. Seguindo a argumentação de Luta pelo Reconhecimento, Honneth (2011) adiciona à forma elementar de reconhecimento através do amor as ideias de respeito e solidariedade, que colocam as pessoas em distintas constelações com diferentes atuações que se podem esperar legitimante. Todas elas ultrapassam a mera afirmação da existência do outro, ou seja, daquilo que se entende por "conhecer", já que mostram uma disposição motivacional em relação ao outro que supõe uma restrição da própria perspetiva egocêntrica e com a qual concedemos ao outro uma autoridade moral sobre nós na interação. A invisibilidade social aparece então como a negação do reconhecimento social.

Para Honneth (2005) os sujeitos humanos são visíveis a outro sujeito, na medida em que este pode identificá-los, de acordo com as características do relacionamento, como pessoas claramente definidas por propriedades, ou seja, quando os nossos parceiros de interação social reconhecem as nossas singularidades e qualidades. $O$ autor propõe uma conceção teórica capaz de corresponder os desafios inerentes às situações de opressão na sociedade, recorrendo ao conceito de invisibilidade social. De acordo com Honneth (2005, p. 42, tradução nossa), "a história cultural oferece inúmeros exemplos nos quais o dominador expressa sua superioridade social aparen- 
tando não perceber aqueles que ele domina"2. Um sujeito poderá atestar a sua visibilidade se forçar o seu parceiro de interação social a reconhecer as propriedades e singularidades que formam a sua identidade.

Das pesquisas histórico-teóricas de Honneth (2008,) destaca-se a consequência, e de certa forma o pressuposto, de que "na relação do ser humano com o seu mundo, o reconhecer (Anerkennen) sempre antecede o conhecer (Erkennen), de tal modo que por "reificação" devemos entender uma violação contra esta ordem de precedência." O reconhecimento espontâneo, de certa forma inconsciente e irracional, aquilo que o autor designa como "realização pré cognitiva do ato de assumir uma determinada postura" (HONNETH, 2008, p. 73), o que leva a aceitar a perspetiva do outro depois de previamente reconhecermos nele uma intencionalidade familiar, é apresentado como pressuposto da interação humana. Esta ação não é racional nem configura "uma tomada qualquer de consciência de motivos" (HONNETH, 2008, p. 73). Esta atitude para Honneth não se reveste de orientação normativa, ainda que ela nos conduza para alguma forma de tomada de posição, que não se apresenta de forma alguma predeterminada. Salienta-se o carácter não epistémico desta forma de reconhecimento elementar, pelo que o autor antepõe às esferas diferenciadas do reconhecimento uma etapa do reconhecimento, que afigura uma espécie de condição transcendental: o reconhecimento espontâneo, não realizado racionalmente, do outro como próximo representa um pressuposto necessário para poder se apropriar de valores morais, à luz dos quais nós reconhecemos aquele outro de forma determinada, normativa. (HONNETH, 2008,)

Não existindo a experiência da proximidade e/ou semelhança do outro, não poderíamos dotar a relação com valores morais ordenadores do nosso agir. Assim, em primeiro lugar, é necessário realizar o reconhecimento elementar, "precisamos tomar parte (Anteilnehmen) do outro

\footnotetext{
2 Do original: "L'histoire culturelle offre de nombreux exemples de situations dans lesquelles les dominants expriment leur supériorité sociale en ne percevant pas ceux qu'ils dominent".
} 
existencialmente, antes de podermos aprender a orientar-nos por normas do reconhecimento" (HONNETH, 2008, p. 73) que nos vinculam a determinadas formas de agir. No processo de socialização, os indivíduos aprendem a interiorizar as normas de reconhecimento específicas da respetiva cultura; deste modo eles enriquecem passo a passo aquela representação elementar do próximo, que desde cedo lhes está disponível por hábito, com aqueles valores específicos que estão corporificados nos princípios de reconhecimento vigentes dentro da sua sociedade. (HONNETH, 2008)

Quais os princípios normativos que são pressupostos em relação ao ser humano, ao afirmar-se que este refere-se sempre aos outros de forma "reconhecedora" (anerkennend)? A resposta a esta pergunta constitui uma preocupação central na reflexão de Honneth ao contribuir para uma teoria da intersubjetividade humana. Honneth tenta orientar a análise sociológica no estudo das pretensões normativas de reconhecimento.

Axel Honneth no seu livro Crítica del agravio moral (2009b) apresenta-nos também uma proposta teórica de reconhecimento da ofensa moral e de ampliação da solidariedade democrática. Honneth desenvolve uma perspetiva em que a ofensa moral não é um simples antecedente da violência recíproca, nem somente o reverso da justiça formal, que teria que castigar para compensar o dano infligido nos direitos legais das pessoas. Mas afigura-se importante interpretar as consequências morais que a ofensa moral interpessoal e os conflitos por reconhecimento desempenham no processo de subjetivação. Honneth pretende recuperar o potencial ético subjacente aos processos de luta por reconhecimento intersubjetivo que são desenvolvidos a partir da experiência de vulnerabilidade e de violação da integridade pessoal; estes pretendem ampliar os horizontes das formas de relação moral - afeto, respeito e solidariedade - e dos vínculos recíprocos, que sustentam a nossa integridade, na forma de autoconfiança, autorrespeito e autoestima.

Neste sentido, as experiências de desprezo e violação moral e os sentimentos de injustiça decorrentes são a fontes das pretensões normativas de reconhecimento, que vão expandindo os vínculos recíprocos e o sentido 
de reconhecimento social. Assim, as violações morais oferecem um padrão normativo e uma fonte de motivação prática mais adequados para Honneth (2009b) do que os princípios da justiça convencional. Paralelamente às três esferas de reconhecimento atrás enunciadas, Honneth (2009b) distingues três formas de violação moral: em primeiro lugar, as formas de ofensa que privam a pessoa da segurança do seu bem-estar físico, como ocorre com os maltratos físicos, a tortura, a violação e o homicídio. Em segundo lugar, as formas de desprezo pela responsabilidade moral das pessoas, que destroem o respeito por si próprias, como seja através de fraude, engano, não cumprir os compromissos, etc. Por fim, existe uma forma de desprezo que passa pela humilhação do outro e por falta grave de respeito, que vai desde a indiferença e invisibilidade, até à estigmatização do outro.

Para Honneth (2009b) resulta fundamental atender à expressão dos sentimentos de desprezo e de injustiça, uma vez que a partir da sua interpretação será possível aprofundar as formas democráticas de reconhecimento intersubjetivo de todas as pessoas e minimizar as possibilidades de serem afetadas pela injustiça social.

Assim, para Honneth, as experiências de desrespeito constituem a base moral da luta por reconhecimento dos indivíduos, ultrapassando determinados padrões institucionalizados. Podemos apontar como exemplos históricos o movimento feminista e os dos povos colonizados, que demonstram que esse substrato moral é capaz de considerar a totalidade das formas de injustiça social, resultantes da depreciação de determinados padrões de estima social. Para Honneth, é somente através de um paradigma normativo que ultrapasse as contingências históricas que se pode examinar a ampla escala de sofrimento humano e fornecer o fundamento moral necessário para renovar a teoria crítica.

Para Honneth a prática de comportamentos desviantes não resultaria apenas em uma reprovação social, mas no impedimento ao indivíduo de um reconhecimento positivo de si mesmo na sua ação. Abre-se assim a possibilidade de transformação da ética coletiva que permita a realização do "Eu". Neste sentido, a luta pelo reconhecimento social das particula- 
ridades do sujeito seria o constante motor de transformação do quadro ético de uma sociedade, de modo a incluir formas de individualidade que em uma dada circunstância são objeto de um reconhecimento precário.

A conceção formal de vida ética desenvolvida por Honneth no final de A luta por reconhecimento tem como implicação política a necessidade de conferir aos sentimentos de desrespeito moral um potencial normativo, que possibilite avaliar a legitimidade de uma ordem social. Uma vez que a situação de vulnerabilidade moral está relacionada com as expectativas de um grupo, tais pretensões, ao serem articuladas, potenciam a ampliação dos processos intersubjetivos de reconhecimento, originando novas capacidades de autorreferência moral, através das quais os sujeitos poderão conceber-se de uma forma renovada.

\section{Reconhecimento, reconstrução normativa e justiça}

A fim de reedificar o alicerce de uma teoria social com conteúdo normativo, nos moldes do projeto anteriormente desenvolvido por Horkheimer para a teoria crítica, Honneth recuperou o projeto filosófico hegeliano de uma luta por reconhecimento. Embora em um primeiro momento se tenha circunscrito a procurar as suas bases no pensamento do jovem Hegel, em obras mais recentes (HONNETH, 2007a; 2010), o autor tenta vincular aquela luta intersubjetiva à conceção de liberdade formulada pelo Hegel maduro, em oposição às visões atomísticas de Kant e Fichte.

Honneth afirma que a teoria da justiça de Hegel tem em comum com o pensamento desses autores a centralidade da ideia de igual liberdade individual para todos e todas. No entanto, a sua teoria distingue-se daquelas ao conceber a liberdade como algo que ultrapassa um simples direito subjetivo ou uma simples autonomia moral. Para Hegel, adotar quaisquer destas visões do conceito de liberdade, de uma forma isolada, conduziria às patologias sociais resultantes da violação do "espírito absoluto" (HONNETH, 2010, p. 25). Nesta tese hegeliana, ainda que de caráter 
metafísico e historicamente situada, Honneth considera haver um núcleo crítico que deverá ser transportado para os nossos dias.

A proposta de Honneth (2007a) de reatualizar a Filosofia do direito de Hegel (1997) não pretende reabilitar nem as condições metódicas da Lógica, nem a conceção básica do Estado de Hegel. Mas despojadas destes elementos, a "Filosofia do direito" de Hegel poderá ser concebida como um projeto de uma teoria normativa daquelas esferas de reconhecimento recíproco cuja manutenção é constitutiva das sociedades modernas (HONNETH, 2007a). Para corresponder a tal desafio, Honneth enuncia os elementos restantes que permitem essa reactualização: o conceito de "espírito objetivo" e a noção de "eticidade".

O conceito de espírito objetivo parece conter a tese que toda a realidade social possui uma estrutura racional, cuja rejeição mediante conceções falsas ou insuficientes tem que conduzir, mesmo onde sejam aplicadas de maneira prática, a consequências negativas na vida social. (HONNETH, 2007a)

No que diz respeito ao conceito de eticidade, Honneth considera que este contém a tese de que na realidade social podem-se encontrar esferas de ação nas quais as inclinações e normas morais, interesses e valores estão fundidos na forma de interações institucionalizadas (HONNETH, 2007a). Pelo que seriam, consequentemente, essas esferas, e não o Estado, a merecer uma caraterização normativa através do conceito de eticidade.

A partir destes princípios, Honneth (2007a) inicia um trabalho de reactualização da teoria do direito de Hegel através de três etapas. Na primeira, apresenta uma teoria da justiça, a partir do conceito hegeliano de "vontade livre" que, tendo sido conceptualizado em oposição às perspetivas atomistas, determina o âmbito total daquilo que devemos chamar de "direito". A dificuldade desta intuição fundamental está relacionada com a tese hegeliana de que a "vontade tem-se a si mesma como objeto" (HONNETH, 2007a, p. 59). Honneth interpreta esta ideia com base na definição hegeliana de amor: "Ser si próprio no outro". Com esta interpretação o enfoque desloca-se para a existência de condições sociais e institucionais, vistas como fundamentais, pois estas deverão permitir as relações comunicativas dos 
sujeitos. Para Honneth (2007a), aquelas esferas, expressas nas instituições e nos sistemas de práticas, que resultem insubstituíveis para possibilitar socialmente a autodeterminação individual, é que são as autenticas portadores de direitos. Desta forma, entende-se a "Filosofia do direito" como a teoria das condições sociais de possibilidade da realização da "vontade livre". O que vai no sentido de uma teoria normativa da justiça social.

Desde esta perspetiva, a teoria do direito de Hegel estrutura-se em três divisões. "Direito abstrato" e "Moralidade" são as duas primeiras, em que Hegel aborda as condições incompletas de realização da vontade livre, na forma que esta assume, respetivamente, de direitos modernos ou na capacidade de autodeterminação moral. Na terceira parte, a "Eticidade", trata das condições completas, distinguindo três esferas de ação comunicativa: a família, a sociedade civil e o Estado. A partir daqui a teoria da justiça articula-se com o diagnóstico da época, constituindo a segunda etapa da proposta de reactualização de Honneth.

Honneth (2007a) compara a pretensão de Hegel com a argumentação de Habermas em Faticidade e Validez (Direito e Democracia: entre facticidade e validade). Para Habermas, a legitimidade da ordem jurídico-estatal deduz-se da garantia das condições de formação democrática da vontade, enquanto em Hegel remonta-se à autorrealização individual para deduzir das suas condições a tarefa de uma ordem jurídica moderna (HONNETH, 2007a). Hegel apresenta uma vasta descrição das conceções contrárias à liberdade, como uma tendência da época. O que dificulta a sua tarefa de dar relevo, no desenvolvimento da sua teoria da justiça, à função necessária que assumem a liberdade jurídica e a liberdade moral relativamente às condições da liberdade comunicativa, que são patentes no conceito de eticidade (HONNETH, 2007a).

Na primeira parte da obra de Hegel, a do direito abstrato, o autor argumenta que apelar a ele é somente uma possibilidade, algo a respeito de todo o conjunto de circunstâncias. Utilizar esta faculdade dependeria de fatores quase caracterológicos e tinha como consequência o sofrimento: Aquela pessoa que articula todas as suas necessidades e propósitos nas categorias do direito formal resulta incapaz de participar na vida social e, 
por isso, sofrerá na indeterminação (HONNETH, 2007, p. 83). Mas, por outro lado, pode-se reconhecer o valor do direito formal relativamente à autorrealização individual, pois o sujeito, percebendo-se como portador de direitos e ao evidenciar os limites impostos pelas relações sociais, tem a oportunidade de retirar-se atrás de toda a eticidade.

Na segunda parte do livro, que corresponde à moralidade, Honneth reconstrói o argumento de Hegel de forma a mostrar a relação entre os limites em que o sujeito tropeça ao conceber unilateralmente de uma forma moral a realização da sua liberdade e as razões que promovem a passagem à esfera da eticidade. A crítica de Hegel dirige-se contra o imperativo categórico kantiano, pois a sua aplicação resulta em desorientação e na sensação de vazio. Kant entendia que o seu imperativo categórico havia de aplicar-se onde houvesse um conflito moral. No entanto, na crítica de Hegel, a formalidade do imperativo levava à abstração do meio social, onde já estão institucionalizados conceitos e pontos de vista morais, e se assim é, o imperativo perde a sua função fundamentadora.

Para que o argumento de Hegel não seja entendido como relativismo moral, Honneth (2007a) argumenta que o conceito de eticidade é um argumento teórico-moral em sentido restrito e que a proposta de compreender a realidade social como encarnação da vontade livre representa um argumento epistemológico e de ontologia social. Ao não considerarmos a eticidade nem a racionalidade suficiente das instituições sociais, que se transformam em uma segunda natureza, o sujeito está abandonado ao vazio interior e à pobreza da ação. Por isso, o caminho para a eticidade deverá ser experimentado como uma libertação, não só por abandonar as conceções incompletas, mas também pelo seu efeito terapêutico sobre uma patologia no mundo da vida que causa sofrimento. Assim, deverá ser compreendido como uma "conquista de uma liberdade afirmativa" (HONNETH, 2007, p. 86). Desta forma, a Filosofia do direito de Hegel apresenta uma fenomenologia das configurações da liberdade, com uma equivalente teoria da justiça, a consciência livre vincula-se ao diagnóstico da época, e estes elementos convergem na doutrina da eticidade. 
O passo final de Honneth é reatualizar a doutrina da eticidade em uma teoria normativa da modernidade. Para tal, estabelece como condições fundamentais a autorrealização e o reconhecimento. Só em uma ação cuja execução é caraterizada mediante o cumprimento de determinadas normas morais pode um sujeito garantir ser reconhecido pelos demais, porque este reconhecimento está determinado precisamente pelas competências morais, que estão estabelecidas mediante as normas de ação correspondentes (HONNETH, 2007a).

Assim, o conteúdo normativo da eticidade é uma articulação das formas de ação intersubjetiva que podem garantir reconhecimento devido à sua qualidade moral. Neste sentido, a família, a sociedade civil e o Estado, constituem-se como esferas sociais, com campos de práticas, que poderão garantir a liberdade individual nas suas configurações modernas que articulam reconhecimento, formação e autorrealização.

A renovada teoria da luta pelo reconhecimento afigura-se como modelo de compreensão dos conflitos sociais como reivindicações éticas que contribuem para a expansão das possibilidades de subjetivação e alteram o quadro ético do todo. A transgressão, assim, vem apontar para a insuficiência ética do coletivo, não do indivíduo transgressor. Inverte-se o foco de intervenção do direito, deixando de estar centrado no indivíduo, na necessidade de adaptá-lo às convenções sociais, para se centrar na sociedade, para a necessidade desta de reconhecer e incluir os mais diversos modos de existência, garantindo-os desde a sobrevivência física até a valorização da sua singularidade.

Tendo em vista a revisão do projeto inicial de Luta por Reconhecimento, passados quase vinte anos, é possível entender El derecho de la libertad, esbozo de una eticidad democrática (2014) como o primeiro livro em que Honneth reelabora a sua teoria de forma sistemática. Nesse sentido, o conceito de reconhecimento passa a cumprir um outro papel: se, na sua tese de habilitação, Honneth desenvolve uma tipologia das formas de reconhecimento, articulando mais propriamente uma relação entre a teoria da subjetividade e a teoria social, a sua atenção volta-se, agora, para uma 
análise de teoria da justiça apoiada em uma teoria crítica da sociedade, cujo conceito central passa a ser o de liberdade - entendida, mais especificamente, a partir da ideia de liberdade social, onde são discutidas as esferas de uma teoria da eticidade democrática (demokratische Sittlichkeit).

Honneth apoia a sua teoria da justiça na análise social, na crítica social e não em princípios formais. É a partir de Hegel que Honneth vai propor uma reformulação do vínculo entre a teoria da justiça e a teoria social, em um dos diálogos mais ricos entre filosofia hegeliana e o debate contemporâneo em filosofia política e teorias da justiça.

Neste sentido, o sugestivo título do livro aponta uma significativa mudança diante de modelos recorrentes no debate sobre teorias da justiça. Trata-se, portanto, de deslocar a ênfase na juridificação e no procedimento da justiça para a reconstrução dos modos de realização do conceito de liberdade individual mediada social e institucionalmente.

Destaca-se, aqui, a importância que o autor concede ao sentido de liberdade individual como pressuposto para a tarefa de uma reconstrução normativa. Nesse sentido, Honneth (2014, p. 31-32, tradução nossa) escreve que:

Na modernidade da sociedade só se pode legitimar a exigência por justiça, quando, de um modo ou de outro, a autonomia do indivíduo não é nem vontade da comunidade nem a ordem natural, mas a liberdade individual que configura a pedra fundamental normativa de todas as representações de justiça. ${ }^{3}$

Mas é somente na terceira parte do livro que se encontra o núcleo propositivo do projeto de Honneth (2014). E é nessa parte que o autor, em distinção do sentido de possibilidade da liberdade referente às liberdades morais e jurídicas, encontra o significado de "realização da liberdade" nos padrões não de um indivíduo tomado isoladamente, mas da liberdade so-

\footnotetext{
3 Do original: "En la modernidade de la sociedad, el reclamo de justiça solo puede ser legitimado publicamente cuando se hace referencia de una u outra manera a la autonomia del individuo; no es la voluntad de la comunidade, nos es el orden natural, sino la libertad individual la que constituye la piedra normativa fundamental de todas las ideias de justicia."
} 
cial expressa em um sentido plural e ampliado de "nós" (das 'Wir). Desse modo, as esferas de realização da liberdade social, seguindo de perto os passos da teoria da eticidade hegeliana, são desenvolvidas enquanto o "nós" das relações pessoais, do "mercado" e, em relação ao âmbito do Estado, na formação democrática da vontade.

De forma diferente de Luta por reconhecimento, na primeira parte, intitulada "relações pessoais", envolve não só o debate sobre a família, mas também compreende discussões sobre relações íntimas (Intimbeziehungen) - cuja tematização oferece um contributo sobre temas, em particular a amizade, menos explorados no debate contemporâneo. $\mathrm{O}$ autor, portanto, retoma algumas ideias já mencionadas em Sofrimento de indeterminação (2007a), onde são sugeridas, diferentemente do sentido institucional que Hegel vira fundamentalmente na pequena família burguesa, outras relações afetivas, tais como amizade e relações amorosas - o que, aliás, faria jus à própria conceção de Hegel de que "amor e amizade" são entendidos nos padrões de liberdade social, do estar-consigo-mesmo-no-outro.

No que concerne à família, por sua vez, Honneth observa as mudanças estruturais ocorridas ao longo da modernidade, mostrando as formas plurais de concepção em torno do modelo familiar. Destaca-se, aqui, a discussão entre as esferas da família e do trabalho, em que as relações afetivas se conjugam com novos papéis desempenhados a partir de lutas por emancipação da mulher. Ao mesmo tempo, o autor discute a importância de ver o cuidado afetivo e a educação dos filhos pelos pais como contribuição social e em um momento ulterior, com o aumento da esperança de vida, o cuidado dos pais pelos filhos, que, em um certo sentido, "tornam-se 'pais' dos seus pais'" (HONNETH, 2014, p. 226). E, aqui, diante da iminência da morte, Honneth encontra no sentido do "consolo" uma forma secular, plena de conteúdo afetivo, de lidar com a transitoriedade da vida. $O$ autor defende que ambas as consequências devem ser tidas em conta por um modelo de políticas públicas.

Se, em relação à família, a reconstrução normativa proposta por Honneth não encontra maiores dificuldades, a discussão sobre o merca- 
do apresenta, provavelmente, uma das partes mais controversas. Com efeito, Honneth vê o mercado como espaço de liberdade social na medida em que possibilitaria a satisfação recíproca de carências e preferências individuais e, nesse sentido, a referência ao mercado é indissociável de uma discussão sobre o seu conteúdo moral: as relações de mercado só podem ser legítimas se são capazes de realizar tais demandas. As evidentes contradições e esgotamento do mercado no seu modelo atual em satisfazer demandas individuais são problemas ocorridos no seu próprio desenvolvimento e que impedem a realização do seu potencial normativo. Não é claro, contudo, se os problemas de desenvolvimento são inerentes ao modo de produção capitalista - como em uma análise marxista ao qual o próprio autor também se refere - ou se deveria haver uma espécie de correção derivada de uma revisão interna ao capitalismo.

O que Honneth propõe é rever os necessários pressupostos "morais" de modo que também o mercado possa assegurar a satisfação socialmente mediada de preferências individuais. E, nesse sentido, Honneth (2014) refere-se ao assim chamado "Adam-Smith problem" (HONNET, 2014, p. 238) - em torno da questão do vínculo entre a teoria moral e a teoria econômica de Smith - defendendo a interpretação de que só é possível fundamentar um livre mercado se são preenchidas condições prévias vinculadas a um conteúdo moral - como sugerem os conceitos de "empatia" em Smith, de "solidariedade" em Durkheim ou de "confiança" em Hegel. Assim, por exemplo, Honneth, na defesa de uma "consciência solidária", prévia também a relações contratuais, alega que

na linguagem escolhida por Hegel é possível expressar a ideia de que a coordenação dos simples cálculos de preferências individuais procedidos no âmbito do mercado só podem ter êxito se os sujeitos envolvidos são reconhecidos não somente juridicamente como parceiros de contrato, mas também moralmente e eticamente ("sittlich") como membros de uma comunidade de cooperação ("kooperierenden Gemeinwesen") (HONNET, 2014, p. 248). 
Honneth em entrevista com Gustavo Pereira (2010) apresenta-nos uma ideia de eticidade pós-tradicional alargada, em uma linha hegeliana, que inclui a vida privada, as formas de relações intimas e, o que aqui se torna importante, certas formas de vida económica. $\mathrm{O}$ autor defende que devemos ter eticidade na vida económica. O mercado devia ter uma forma normativa. O mercado neoliberal que temos hoje não é uma forma ética de mercado. Já Hegel e mais tarde Durkheim tinham tido esta ideia, que o mercado económico capitalista só terá uma forma ética se for regulado em um sentido de inclusão de todos e de cada um. Que cada ser humano seja especificamente incluído no mercado, de forma a que sejam possíveis as correspondentes formas de estima social.

Passando à esfera do Estado, Honneth refere-se às discussões contemporâneas sobre os déficits de legitimidade das instituições europeias e os esforços de um projeto comum para a União Europeia. E, ao voltar-se para o sentido da liberdade social, Honneth encontra tais padrões, no que concerne à relação dos cidadãos no âmbito da esfera do Estado, a partir da discussão sobre a "formação democrática da vontade" (HONNETH 2014, p. 385).

Não deixa de surpreender, desse modo, que é neste capítulo onde Honneth articula uma maior interlocução com a proposta habermasiana - destacando-se, além do próprio conceito, recorrente também em Habermas, de "formação da vontade" (Willensbildung), temas como esfera pública (Öffentlichkeit) e "patriotismo constitucional", cuja interpretação foi retomada por Habermas a partir da discussão do filósofo e cientista político alemão Dolf Sternberger. No entanto, também aqui Honneth tece uma crítica ao sentido procedimental e aos limites do debate atual na medida em que está voltado fundamentalmente para a esfera jurídica. Ainda que as garantias jurídicas de liberdade comunicativa e de participação (que podem ser expressas no sentido da liberdade jurídica, mencionada anteriormente) sejam fundamentais, elas por si só não asseguram a expressão de uma esfera pública engajada. Junto a elas devem-se acrescentar) o papel da comunicação social, a disposição 
dos cidadãos em participar dos debates e manifestações públicas, e um sentimento de solidariedade cívica.

Se esta interpretação indica os impasses de uma pretensão normativa forte em relação a essas difíceis premissas, ela também mostra um sentido mais imanente de análise social. Pois, se, por um lado, a dificuldade de realizabilidade de tais premissas indicam os limites de uma teoria normativa, por outro, são as próprias fixações de uma teoria normativa baseada em princípios, já mencionados por Honneth, que podem resultar na negligência ou limitação de uma dimensão social efetiva e do potencial de análise crítica. E é nesse sentido que também em relação ao debate sobre patriotismo constitucional Honneth insiste, com uma certa dose de realismo político, que haja um sentido efetivo de sentimento de pertencimento ao projeto compartilhado por uma esfera pública que se veja reconhecida e representada por suas instituições. Somente assim é possível falar de uma vontade política legitimada, do qual depende - no caso da União Europeia - o sentido de um “'demos' europeu” (2014, p. 444) e de uma "esfera pública transnacional e engajada"2014, p. 445).

Pelo que se pode entrever, a aposta honnethiana na reconstrução normativa não é imune a críticas. E aqui poderíamos nomear basicamente dois problemas ou limitações. O primeiro, já mencionado, é o sentido fundamentalmente eurocêntrico da reconstrução que Honneth propõe. Um segundo problema consiste em um necessário ponto de partida tomado para a reconstrução proposta. Com efeito, o autor precisa recorrer a um determinado sentido de télos que justifique os critérios de sua reconstrução: É somente por já tomar de antemão o conceito de liberdade social que é possível reconstruir quadros institucionais de uma determinada maneira vinculados àquele conceito. Este problema dos critérios da reconstrução, atrelado ao recorte dos exemplos, impõe um limite à proposta de uma reconstrução com pretensões de oferecer um conteúdo universal mínimo, ainda que os conteúdos específicos não sejam previamente estabelecidos - como Honneth propunha já em Luta por reconhecimento (2011). 
Nesse sentido, tanto as qualidades como as limitações de El derecho de la libertad, esbozo de una eticidad democrática (2014) parecem ser consequências da própria ambição ao qual o livro se propõe. Por um lado, mostra-se promissora a tentativa de fornecer não uma crítica externa baseada em princípios formais, mas uma crítica interna a partir dos próprios processos históricos de diferenciação na modernidade; por outro, no entanto, a busca por uma ampliação teórica de pretensões universalistas pode facilmente revelar imprecisões. Tendo em vista uma atual situação teórica em que pretensões universalistas são constantemente revistas, não devemos deixar de situar a teoria de Honneth em um determinado contexto histórico e encarnada em cada situação de interação humana.

\section{Considerações finais}

Assim, em forma de síntese, Axel Honneth apresenta um conceito de luta social que enfatiza a dimensão ética da injustiça, propondo novos parâmetros para a teoria crítica. A sua proposta consiste em analisar os padrões concretos de desrespeito que conduzem os indivíduos às lutas sociais por reconhecimento, nas quais há uma ampliação contínua das perceções que os indivíduos têm dos seus atributos singulares.

A partir de uma análise do percurso bibliográfico de Honneth iniciada no conceito de reconhecimento, encarado como uma necessidade fundamental do ser-humano, apresentou-se uma teoria da justiça que procura especificar as condições intersubjetivas de autorrealização individual. Uma teoria da justiça que se efetiva na reconstrução das práticas e condições de reconhecimento já institucionalizadas, analisando as instituições sociais em um sentido amplo. Honneth pretende aproximar a conceção normativa da justiça da análise sociológica das sociedades modernas, através da reconstrução normativa e ao colocar a ênfase na liberdade social, baseada na dimensão intersubjetiva das instituições de reconhecimento.

A concepção de justiça de Honneth (2009c) assenta, em primeiro lugar, na substituição do esquema distributivo pela concepção de uma inclusão 
de todos os sujeitos nas relações de reconhecimento desenvolvidas em cada situação; em segundo, no lugar da construção de um procedimento fictício deverá ser colocada uma reconstrução normativa que revele histórico-geneticamente as normas morais fundamentais daquelas relações de reconhecimento; e, por último, o olhar exclusivo sobre a atividade reguladora do estado de direito deverá ser complementado por uma consideração descentralizada de agências e organizações não estatais.

Uma teoria da justiça que procede reconstrutivamente está hoje colocada diante do desafio de defender em nome da autonomia individual não apenas um princípio normativo, mas logo três destes princípios: dependendo da esfera social a que ela se volta, ela deve destacar e fortalecer o ponto de vista moral da igualdade deliberativa, da justiça das necessidades e da justiça do desempenho. Um pluralismo destes, por mais difícil que pareça de manejar, vem ao encontro das diferenciações com as quais os próprios sujeitos operam topicamente em questões da justiça; como revelam hoje uma série de pesquisas empíricas, também eles normalmente distinguem nos problemas ligados à cooperação no seu cotidiano exatamente os três âmbitos mencionados, para aplicar a cada um deles o correspondente princípio de justiça (HONNETH, 2009). Podemos afirmar que o pensamento de Honneth representa uma contribuição decisiva no debate contemporâneo de teorias da justiça e da filosofia política enquanto coloca em questão posições já tomadas como pressupostas em grande parte desse debate, procurando oferecer uma resposta própria no âmbito de uma filosofia política renovada. Permanece, portanto, promissor o ponto de partida do autor de desenvolver uma teoria da justiça nos passos de uma análise crítica da sociedade, mesmo que a tentativa de Honneth dependa historicamente de seu próprio contexto.

\section{Referências}

Ellison, Ralph El hombre invisible. Barcelona: Lumen. 1984. 
Hegel, Georg Princípios da filosofia do direito. Tradução de Orlando Vitorino. São Paulo: Martins Fontes, 1997.

Hegel, Georg. Fenomenologia do Espírito. Rio de Janeiro: Editora Vozes, 1992. Honneth, Axel. Crítica del agravio moral. Patologias de la sociedad contemporánea. Traducción de Peter Strandt Diller. Buenos Aires: Fondo de Cultura Económica, 2009b. https://doi.org/10.22201/fcpys.2448492xe.2004.190.42443

Honneth, Axel. El derecho de la libertad. Esbozo de una eticidad democrática. Tradução de Graciela Calderón. Buenos Aires: Katz Editores, 2014.

Honneth, Axel. Disrespect: the normative foundations of critical theory. Tradução de John Farrel e Joseph Ganahl. Malden: Polity Press, 2007b.

Honneth, Axel. Invisibilité: sur l'épistémologie de la reconnaissance. Tradução de Françoise Gollain e Christian Lazzeri. Réseaux, Paris, $\mathrm{n}^{\circ}$ 129-130, p.39-57. 2005. Disponível em: https://www.cairn.info/revue-reseaux1-2005-1-page-39. htm\#. Acesso em: 12 jun. 2013. https://doi.org/10.3917/res.129.0039

Honneth, Axel. Luta por reconhecimento: para uma gramática moral dos conflitos sociais. Tradução de Jorge Telles de Menezes. Lisboa: Edições 70, 2011. Honneth, Axel. "Observações sobre a reificação". Tradução de Emil Sobottka e Giovani Saavedra. Civitas: Revista de Ciências Sociais, Porto Alegre, v. 8, n. 1, p. 68-79, jan./abr. 2008. https://doi.org/10.15448/1984-7289.2008.1.4322 Honneth, Axel. Patologias de la Razon. Historia y actualidad de la Teoría Crítica. Traducción de Griselda Mársico. Madrid: Katz. 2009a. https://doi. org/10.2307/j.ctvm7bcdz

Honneth, Axel. "Recognition and Justice: Outline of a plural theory of Justice". Tradução de Andrew Inkpin. Acta Sociológica, [México], v. 4, p. 351-364, 2004. https://doi.org/10.1177/00001699304048668

Honneth, Axel. Sofrimento de indeterminação. Tradução de Rurión Soares Melo. São Paulo: Editora Singular, 2007a.

Honneth, Axel. A textura da justiça. Sobre os limites de procedimentalismo contemporâneo. Civitas: Revista de Ciências Sociais, Porto Alegre, v. 9, n. 3, p. 345-368, set./dez. 2009c. https://doi.org/10.15448/1984-7289.2009.3.6896 Pereira, Gustavo. Reconocimiento y critérios normativos. Entrevista a Axel Honneth, Andamios, México, v. 7, n. 13, p. 323-334, mayo-agosto. 2010. https://doi.org/10.29092/uacm.v7i13.128 
Stern, Daniel. O mundo interpessoal do bebê. Tradução de Maria Adriana Veríssimo Veronese. Porto Alegre: Artes Médicas,1992.

\section{Endereço Postal}

Centro de Investigação em Ciência Política Escola de Economia e Gestão. Universidade do Minho, Campus de Gualtar, 4710-057 Braga, +351 253 $604518,+351253601947$ 